\title{
Visibilizando quem cuida, suas experiências e percursos de vida
}

\section{The caring self: the work experiences of home care aides.}

STACEY, Clare L.

London: Cornell University Press, 2011 . p. 199.

O envelhecimento demográfico é um fenómeno que caracteriza a grande maioria das sociedades contemporâneas e compreende modificações que vão muito além da mudança da estrutura do perfil etário das populações: mudanças sociais, económicas, culturais e políticas, com profundas repercussões no campo da saúde, no sistema de pensões, na política de habitação, na assistência médica e no domínio do apoio individual às pessoas idosas e respetivas famílias.

O aumento das necessidades de cuidado é uma das consequências desse fenómeno sobre a qual muito se tem escrito, sobretudo no âmbito dos estudos sobre o cuidado. Não é, portanto, um tema de reflexão novo, mesmo para Clare L. Stacey, no sentido em que essa Professora Assistente de Sociologia da Universidade do Estado de Kent, EUA, tem trabalhado a questão do cuidado, relacionando-a com temas como as desigualdades sociais, a saúde e questões de género.'

Em The Caring Self: the work experiences of home care aides, encontramos Stacey a trabalhar um tema que lhe é caro, com o qual consegue realizar um trabalho atípico no contexto científico sobre a produção de cuidado. Diferente porque parte de um objeto analítico que tende a ser constantemente invisibilizado - os/as cuidadores/as domiciliários - e devido à metodológica seguida - a combinação entre entrevistas em profundidade com a observação etnográfica dos contextos de produção de cuidado. Ao escolher olhar para quem cuida $e$ ao fazê-lo nos contextos onde essas pessoas realizam o seu trabalho, Stacey constrói um trabalho importante não só para quem estuda a produção de cuidado, mas também para os temas do trabalho, das desigualdades sociais e das questões de género. 
É interessante perceber que inicialmente Stacey não pretendia estudar os/as cuidadores/ as, mas sim compreender como os idosos e as pessoas com doenças crónicas, nomeadamente, aqueles/as com baixos rendimentos, conseguiam viver num contexto que as invisibilizava. No entanto, chegada ao terreno, ao contactar com a realidade quotidiana, apercebe-se da invisibilidade e ausência de reconhecimento sofridas por quem cuida.

A descrição de Stacey desse momento é fundamental para compreendermos a mudança de objeto analítico. Confrontada com novas interrogações, nascidas da observação de uma situação específica, mas que trespassam largamente o âmbito daquela relação, a autora decide fazer uma (re)focalização teórica face ao seu projeto inicial, e isso dá um enorme peso a observação etnográfica no contexto dessa obra.

Partindo daquelas questões, a autora constrói um trabalho que procura perceber como é que os/as cuidadores/as domiciliares pagos encontram significado e identidade no trabalho de cuidar - o que autora chamou the caring self - dentro de um contexto de real desvantagem estrutural (pobreza, aumento do volume de trabalho, baixos salários e poucos benefícios). Tendo isso por base, o livro divide-se em duas grandes partes.

Na primeira parte, constituída pelos dois primeiros capítulos, a autora tenta perceber os percursos dos/as cuidadores/as. Ao traçar tais percursos, percebe duas questões transversais a todas as pessoas que entrevistou: o contexto de desvantagem estrutural a que estão sujeitas e a existência de experiências passadas como cuidadores/as de familiares ou amigos/as.

No primeiro capítulo, "Os custos do cuidado", é feita uma discussão sobre a correlação entre a desigualdade social (de origem) dos/as cuidadores/as e a prestação de cuidados domiciliários. Somos introduzidos nessa questão pela história de Lette, uma mulher mexicana emigrada nos EUA, cuja narrativa torna evidente como fatores políticos, económicos e biográficos "empurram" os indivíduos para o único trabalho disponível no setor dos serviços, um trabalho que é desigual, invisível e mal pago. A esmagadora maioria das pessoas que aceitam esse trabalho são mulheres com baixos níveis de escolaridade e provenientes de contextos desfavorecidos, para as quais não existem outros trabalhos e cuja aceitação do trabalho presente não permite suplantar as suas condições de origem, devido aos baixos salários auferidos e aos benefícios serem praticamente inexistentes.
Esse primeiro capítulo, no entanto, não se fica pela conclusão de que, de um modo geral, os cuidados são prestados em contexto de grande pobreza. Stacey vai mais longe, quando tenta perceber de que forma as biografias pessoais dos/as cuidadores/as têm importância para compreender a sua relação com o cuidado. Analisa, por isso, as "trajetórias de cuidado" dessas pessoas, concluindo que, na maioria dos casos, elas haviam cuidado, gratuitamente, de pessoas que lhe eram próximas antes de se tornarem cuidadores/as formais. O cuidado não era algo novo nas suas vidas, sendo essa familiaridade com o fenómeno um fator justificativo para sua posição atual, ou seja, cuidar é uma competência "natural" que mobilizaram inicialmente para cuidarem gratuitamente $e$ agora serve de mais valia para desempenharem as suas funções no mercado de trabalho pago. Ao colocarem em enfâse essa competência natural, em vez de evidenciarem os constrangimentos que anteriormente levaram a assumir várias obrigações de cuidado, parecem, segundo mostra a autora, não ter consciência, nomeadamente as mulheres, da pressão cultural existente para esse cuidar.

No segundo capítulo, "Fazendo o trabalho sujo", conhecemos melhor, através de uma descrição etnográfica, como são prestados os cuidados domiciliários pagos. A natureza e a intensidade (física e emocional) das tarefas desempenhadas levam Stacey a referir-se ao cuidado como um "trabalho sujo". "Sujo" essencialmente pelos impactos negativos acarretados a quem cuida. Desde o desgaste físico, ao psicológico, passando novamente pelos baixos salários e a ausência de proteção social, essas pessoas estão sujeitas a um trabalho muito exigente e pesado que nem sempre conseguem gerir bem.

Apesar disso, elas desenvolvem laços entre si, que tendem a valorizar nos seus discursos, e isso complexifica as relações. Cuidar dia e noite de pessoas geralmente sozinhas e/ou deprimidas não é fácil. Se a isso juntarmos o facto de que muitos/as cuidadores/as cuidam mais horas que aquelas que estão estabelecidas nos seus contratos de trabalho, fazendo-o sem terem qualquer tipo de compensação financeira por isso, percebemos que essas relações não podem ser apenas explicadas por questões utilitaristas; e, embora essa componente emocional faça com que quem cuida assuma mais tarefas que as devidas, o que acarreta uma subcarga física e emocional maior do que se não o fizesse, não podemos ignorar que essas 
mesmas pessoas dizem que escolheram ser cuidadores/as domiciliários pagos porque essa atividade Ihes permitiria desenvolver laços (afetivos) com outras pessoas, existindo, portanto recompensas afetivas e afirmação da identidade, que se conseguem nessa atividade.

Por isso, na segunda parte do livro, inaugurada no terceiro capítulo, "As recompensas de cuidar", Stacey debruça-se sobre as gratificações do trabalho de cuidar. À primeira vista, pode parecer contraditória a existência de recompensas positivas num trabalho tão duro $e$ tão desigual, mas já vimos como quem cuida aprende a lidar com um contexto que parece não ter nada de benéfico para si, dando importância à componente afetiva, elemento relevante para a construção do the caring self

O the caring self é uma identidade situada que permite aos/às cuidadores/as "[...] comunicarem a si mesmos e aos outros que o seu trabalho é motivado por razões altruístas e de grande qualidade". ${ }^{2}$ Através desse contributo, ficamos a perceber o porquê de essas pessoas continuarem a cuidar, apesar do estigma e exploração de que são alvos. Isso permite dar o salto além da evidência generalizada de que essas pessoas cuidam porque não existem melhores alternativas de trabalho. É certo que tal acontece. No entanto, o reconhecimento da existência do the caring self mostra-nos o outro lado da realidade, muitas vezes esquecido nesse tipo de estudos: é que muitas pessoas escolhem fazer esse trabalho. Claro que a formação dessa identidade não é inume a fatores como raça classe e género, os quais são cruciais para o modo como se realizam e se sentem no trabalho. Não é, portanto, estranho que mulheres e homens sintam e realizem o seu trabalho diferentemente, tampouco que as cuidadoras mulheres afro-americanas experienciem situações de descriminação racial que profundamente afetam não só desenvolvimento, mas também a sua narrativa sobre o cuidado.

Já no quarto capítulo, "Organizando o cuidado domiciliário", Stacey explora a questão da defesa dos trabalhadores desse setor especificamente através da sua sindicalização. A autora conclui que seria importante ouvir a voz dessas pessoas e dar-Ihes destaque nas investigações sobre o trabalho e o sindicalismo, o que não tem acontecido. Percebe também que poucos/as trabalhadores/as estão sindicalizados e que existe um desfasamento entre os interesses dessas pessoas e a agenda dos sindicatos.

Por fim, no último capítulo, "Conclusão: melhorar as condições de prestação do trabalho pago", Stacey sumariza as principais questões debatidas nessa obra, com destaque para as sobre a identidade e a desigualdade existentes no cuidado domiciliário. Afirma ainda a importância dos resultados empíricos aos quais chegou nessa investigação, nomeadamente para as discussões sobre a prestação de cuidado. Não deixa, contudo, de alertar que, embora o the caring self reforce o compromisso entre os/as cuidadores/as e as pessoas cuidadas, ele é "perigoso" especialmente para as mulheres, porque essencializa seu papel como cuidadoras, focando as suas competências naturais para cuidar, e obscurece aquela que deveria ser a questão: a remuneração digna do trabalho de cuidar.

No início deste texto, dissemos que a obra de Stacey interessava a um público mais amplo que aquele que à partida o título parecia anunciar. Esta resenha, agora a chegar ao fim, dá conta da complexidade das questões trazidas por essa obra e dos muitos contributos que nos deixa. Stacey coloca em evidencia aspetos muitas vezes esquecidos nos trabalhos sobre a produção de cuidado. Destaque para os "percursos de cuidado" dos/as cuidadores/as, essenciais para compreendermos como quem cuida vê o cuidado e o seu papel, ou a importância do contexto em que o cuidado é produzido para percebermos o modo como as relações se desenvolvem, a relevância dada aos laços afetivos desenvolvidos nas relações de cuidado e o papel que assumem na construção do the caring self.

Stacey, não obstante, esquece outros aspetos que tornariam o seu trabalho ainda mais interessante. Em primeiro lugar, dá pouca relevância ao papel da pesquisa etnográfica para essa investigação, apesar de essa ter sido uma mais-valia para a realização desse trabalho e um dos aspetos que o tornam atípico. Depois apesar da importância dada aos laços afetivos para perceber o que leva as pessoas a cuidarem, a autora esquece um contributo teórico que the teria sido muito útil para aprofundar essa questão. Refiro-me ao paradigma da dádiva. Por fim, penso que seria de esperar mais discussão teórica feminista por parte de uma autora que tem trabalhado a questão. A obra em tudo teria ganho com uma maior problematização sobre a questão entre o cuidado e as mulheres e a recuperação de teóricas como Carol Gilligan ou Eva Feder Kittay.

\section{Notas}

' Destaque para a sua tese de doutorado, que analisa a prestação de cuidado partir da teoria feminista (Clare L. STACEY, 2004).

${ }^{2}$ Clare L. STACEY, 2011, p. 107. 


\section{Referências}

STACEY, Clare L. Love's labor's learned: experiences of home health workers of caring for eldery and disabled adults. 2004. Tese (Doutorado em Teoria Feminista e Pesquisa) Universidade da Califórnia, Davis, 2004.

Joana Margarida Pimentel Mateus Alves Faculdade de Economia da Universidade de Coimbra/ Centro de Estudos Sociais (FEUC/CES) 